\title{
Total and segmental colonic transit time in constipated patients with Chagas' disease without megaesophagus or megacolon
}

S.L. Santos ${ }^{1}$

I.K. Barcelos ${ }^{2}$ and

M.A. Mesquita ${ }^{1}$

\author{
1Disciplina de Gastroenterologia, Departamento de Clínica Médica and \\ 2Departamento de Radiologia, Faculdade de Ciências M édicas, \\ Universidade Estadual de Campinas, Campinas, SP, Brasil
}

\section{Correspondence \\ M.A. Mesquita \\ Disciplina de Gastroenterologia \\ Departamento de Clínica Médica \\ FCM, UNICAMP \\ Caixa Postal 6111 \\ 13081-970 Campinas, SP \\ Brasil \\ Fax: +55-19-289-1682}

Publication supported by FAPESP.

Received September 28, 1998 Accepted September 27, 1999

\section{Abstract}

Manometric and pharmacological tests have shown that motor abnormalities may occur in the non-dilated colons of chagasic patients. In order to investigate the presence of abnormalities of colonic function in constipated patients with Chagas' disease (ChC) without megaesophagus or megacolon, studies of total and segmental colonic transit time with radiopaque markers were performed on $15 \mathrm{ChC}$ patients, 27 healthy volunteers and 17 patients with idiopathic constipation (IC). The values obtained for the control group were similar to those reported in the literature (total colonic time: $34.1 \pm 15.6 \mathrm{~h}$; right colon: $9.9 \pm 7.3 \mathrm{~h}$; left colon: $10.8 \pm 10 \mathrm{~h}$, and rectosigmoid: $12.6 \pm 9.9 \mathrm{~h}$ ). Colonic transit time data permitted us to divide both IC and ChC patients into groups with normal transit and those with slow colonic transit. Colonic inertia was detected in $41 \%$ of IC patients and in $13 \%$ of ChC patients; left colon isolated stasis (hindgut dysfunction) was detected in $12 \%$ of IC patients and $7 \%$ of $\mathrm{ChC}$ patients, and outlet obstruction was detected in $6 \%$ of IC patients and $7 \%$ of ChC patients. There were no significant differences in total or segmental colonic transit times between slow transit IC and slow transit ChC patients. In conclusion, an impairment of colonic motility was detected in about $30 \%$ of constipated patients with Chagas' disease without megaesophagus or megacolon. This subgroup of patients presented no distinctive clinical feature or pattern of colonic dysmotility when compared to patients with slow transit idiopathic constipation.

\section{Key words}

- Colonic transit

- Chagas' disease

- Constipation

- Radiopaque markers

- American trypanosomiasis

\section{Introduction}

Chronic intestinal constipation is one of the most frequent complaints in clinical practice (1). In countries like Brazil, where Chagas' disease is endemic, constipation may reflect disorders of colorectal motility induced by the intrinsic denervation seen in organs affected by this disease $(2,3)$. Usually, the diagnosis of chagasic colopathy is made only at the megacolon stage. However, studies on small groups of patients using pharmacological tests $(4,5)$ or manometry $(6,7)$ have shown the presence of neural and motor abnormalities in nondilated colons. This suggests that, as already shown for the 
esophagus (8), the study of colonic motility may identify functional abnormalities in a stage preceding colon dilation.

The assessment of total and segmental colonic transit time (CTT) with ingested radiopaque markers $(9,10)$ has been widely employed to evaluate colorectal function in constipated patients. It is a simple noninvasive technique, readily applicable within the clinical context, which allows patients to be classified into four groups: intestinal constipation with normal colonic transit time, colonic inertia (prolonged transit time throughout the colons, especially the right colon), hindgut dysfunction (prolonged transit time in the left colon, but normal in the right one), and outlet obstruction (prolonged transit time in the rectosigmoid but normal in the remaining areas).

In the present study, this technique was used to evaluate constipated patients with Chagas' disease (ChC) without megaesophagus or megacolon in order to investigate: 1) whether abnormalities of colonic function could be demonstrated at this stage of the disease and 2) to compare these abnormalities with those found in a group of patients with idiopathic intestinal constipation (IC).

\section{Material and Methods}

\section{Study population}

Table 1 shows the clinical features of the study population. Informed written consent was obtained from all subjects involved in the study. The protocol was approved by the Ethics Committee of the Hospital das Clínicas, UNICAMP.

Control group. Twenty-seven healthy volunteers (14 males and 13 females) were recruited from the medical and paramedical staff. The selection criteria included a stool frequency of 2 stools/day to 3 stools/week, no difficulty in passing stools and normal stool consistency. No subject was taking any medication known to affect gastrointestinal motility or reported changes in bowel movements induced by stress. No volunteer had an epidemiological background for Chagas' disease.

Patients with IC. This group consisted of 17 patients (16 females and 1 male) who were referred to our outpatient clinic for evaluation of chronic constipation, defined as less than 3 stools/week and passing of hard stools for at least one year. All patients had barium enema to document the absence of any organic colonic lesions and serologic tests to exclude Chagas' disease. There was no clinical evidence of diabetes mellitus, collagen disease or neurological disorders.

Patients with ChC. These patients were selected from a group regularly followed up at GEDOCH (Chagas' disease study group) with positive serologic reactions (complement fixation test and/or immunofluorescence reaction) for Chagas' disease, with no evidence of heart failure, megaesophagus or megacolon, with the latter two being confirmed by esophagogram and barium enema. Fifteen consecutive patients (10 females and 5 males) who also fulfilled the criteria for a diagnosis of chronic constipation in a separate interview assessing specifically their bowel habits were enrolled in the study. There was no clinical evidence of diabetes mellitus or collagen disease in this group. The symptoms of constipation were similar to those reported by IC, but fewer patients reported the use of laxatives to promote evacuation (Table 1).

\section{Colonic transit studies}

Total and segmental CTT was assessed as previously described by Metcalf et al. (10). Patients were asked to maintain their usual diet and received a fiber supplement of $20 \mathrm{~g} /$ day $\left(\right.$ Metamucil ${ }^{\circledR}$, Procter \& Gamble, São Paulo, SP, Brazil) for one week before and during the study. Laxatives and medications known to affect colonic motility were not permitted during the study. All partici- 
pants ingested 24 radiopaque markers contained within a gelatin capsule(SITZMARKS ${ }^{\circledR}$, Konsyl Pharmaceuticals Inc., Fort Worth, TX, USA) at the same time, after breakfast, on three consecutive days. An abdominal Xray was taken on days 4 and 7 at the time of marker ingestion. Markers were identified and counted on the abdominal films. The right colon, left colon and rectosigmoid were recognized by bony landmarks and/or by their clear identification due to gas shadows as described by Arhan et al. (9). The spinal processes and imaginary lines from the fifth lumbar vertebra to the pelvic outlet served as landmarks.

Total and segmental CTT were then calculated using the following formula:

$$
\Delta t=\frac{T}{N} \sum_{i=1}^{j} n_{i}
$$

where $\Delta \mathrm{t}=$ mean transit time, $\mathrm{T}=$ time interval between $\mathrm{X}$-rays, $\mathrm{N}=$ number of ingested markers, $\mathrm{j}=$ number of $\mathrm{X}$-rays taken, and $n_{i}=$ total number of markers present on a given film sector at time $t_{i}$. Since the abdominal X-rays were always taken at $72-\mathrm{h}$ intervals and the total number of markers was kept constant at 72 , the above formula can be simplified to:

$$
\Delta t=\sum_{i=1}^{j} n_{i}
$$

\section{Statistical analysis}

Results are reported as mean $\pm \mathrm{SD}$. The upper limits of normality of colonic transit times were considered as the mean $+2 \mathrm{SD}$. The results were analyzed by the MannWhitney test for comparison of quantitative data and by the chi-square test or Fisher's exact test for comparison of qualitative data. Differences were considered statistically significant when $\mathrm{P}<0.05$.

\section{Results}

Table 2 shows the mean values of total and segmental CTT for controls and patients.

\section{Control group}

The upper limits of normality for total and segmental CTT were: total colonic transit time $=65 \mathrm{~h}$; right colonic transit time $=25$ $\mathrm{h}$; left colonic transit time $=31 \mathrm{~h}$, and rectosigmoid transit time $=32 \mathrm{~h}$. No statistically

Table 1 - Clinical features of the study population.

IC, Idiopathic constipation; ChC, Chagas' disease constipation. $* \mathrm{P}<0.05$ vs controls and ${ }^{* *} \mathrm{P}<0.05$ vs ChC ( $\chi^{2}$ and Fisher's exact tests).

\begin{tabular}{lccc}
\hline Variables & $\mathrm{IC}(\mathrm{N}=17)$ & $\mathrm{ChC}(\mathrm{N}=15)$ & Control $(\mathrm{N}=27)$ \\
\hline Mean age \pm SD (years) & $35 \pm 11$ & $48 \pm 11^{*}$ & $41 \pm 12$ \\
Gender (\% females) & $94.2^{*}$ & $66.6^{*}$ & 48.1 \\
Symptoms duration (years) & $>7$ & $>10$ & - \\
Bowel movements/week & 1 & $1-2$ & $3-14$ \\
Straining (\%) & 71 & 80 & - \\
Hard stools (\%) & 94 & 93 & - \\
Laxative use (\%) & $100^{* *}$ & 66.6 & -
\end{tabular}

Table 2 - Total and segmental colonic transit time (CTT) in patients with idiopathic constipation (IC) and constipated patients with Chagas' disease (ChC).

Data are reported as means $\pm S D$ in hours. In patients with slow transit constipation the values of total CTT are above the upper limits of normality. TCTT: Total CTT; RCTT: right CTT; LCTT: left CTT, and RSTT: rectosigmoid transit time.

\begin{tabular}{lcccc}
\hline & TCT & RCT & LCT & RSTT \\
\hline Controls & $34.1 \pm 15.6$ & $9.9 \pm 7.4$ & $10.8 \pm 10$ & $12.6 \pm 10$ \\
Upper normal limits & 65 & 25 & 31 & 32 \\
Normal transit IC & $39.2 \pm 17$ & $18.1 \pm 15$ & $12.2 \pm 13.1$ & $9 \pm 6$ \\
Normal transit ChC & $42.5 \pm 15.1$ & $11.0 \pm 10$ & $12.8 \pm 10$ & $17.9 \pm 13$ \\
Slow transit IC & $110.4 \pm 30.4$ & $36.4 \pm 27.3$ & $46.0 \pm 29$ & $28 \pm 24.6$ \\
Slow transit ChC & $100.2 \pm 25.6$ & $25.7 \pm 17.3$ & $45.2 \pm 41.7$ & $29.2 \pm 31.2$
\end{tabular}

Table 3 - Effect of age and gender on total and segmental colonic transit times (CTT) in 27 healthy volunteers.

Results are reported as mean \pm SD hours. For abbreviations see legend to Table 2 .

\begin{tabular}{llrrr}
\hline & \multicolumn{1}{c}{ TCTT } & \multicolumn{1}{c}{ RCTT } & \multicolumn{1}{c}{ LCTT } & \multicolumn{1}{c}{ RSTT } \\
\hline Male $(\mathrm{N}=14)$ & $30.7 \pm 17.1$ & $9.4 \pm 6.9$ & $8.7 \pm 11.4$ & $12.1 \pm 9.9$ \\
Female $(\mathrm{N}=13)$ & $37.7 \pm 13.5$ & $7.0 \pm 8.1$ & $13.5 \pm 8.1$ & $14.5 \pm 10.2$ \\
Age $>$ 40 years $(\mathrm{N}=8)$ & $32.3 \pm 11$ & $13.2 \pm 6.5$ & $10.4 \pm 9.7$ & $11.5 \pm 12.2$ \\
$\quad<$ 40 years $(\mathrm{N}=19)$ & $34.8 \pm 17.2$ & $10.2 \pm 7.9$ & $11.0 \pm 10.4$ & $13.7 \pm 10.5$
\end{tabular}


significant effect of age or gender on colonic transit times was demonstrable (Table 3), although there was a trend for women to present a slower left colon transit than men.

\section{Patient groups}

Total CTT. No patient denied evacuation

Figure 1 - Total colonic transit time (TCTT) in patients with idiopathic constipation (IC) and constipated patients with Chagas' disease (ChC) without megacolon. The horizontal dotted line indicates the upper limits of normality of the test. Both IC and ChC have been divided into those with normal transit and those with slow transit on the basis of the dotted line.
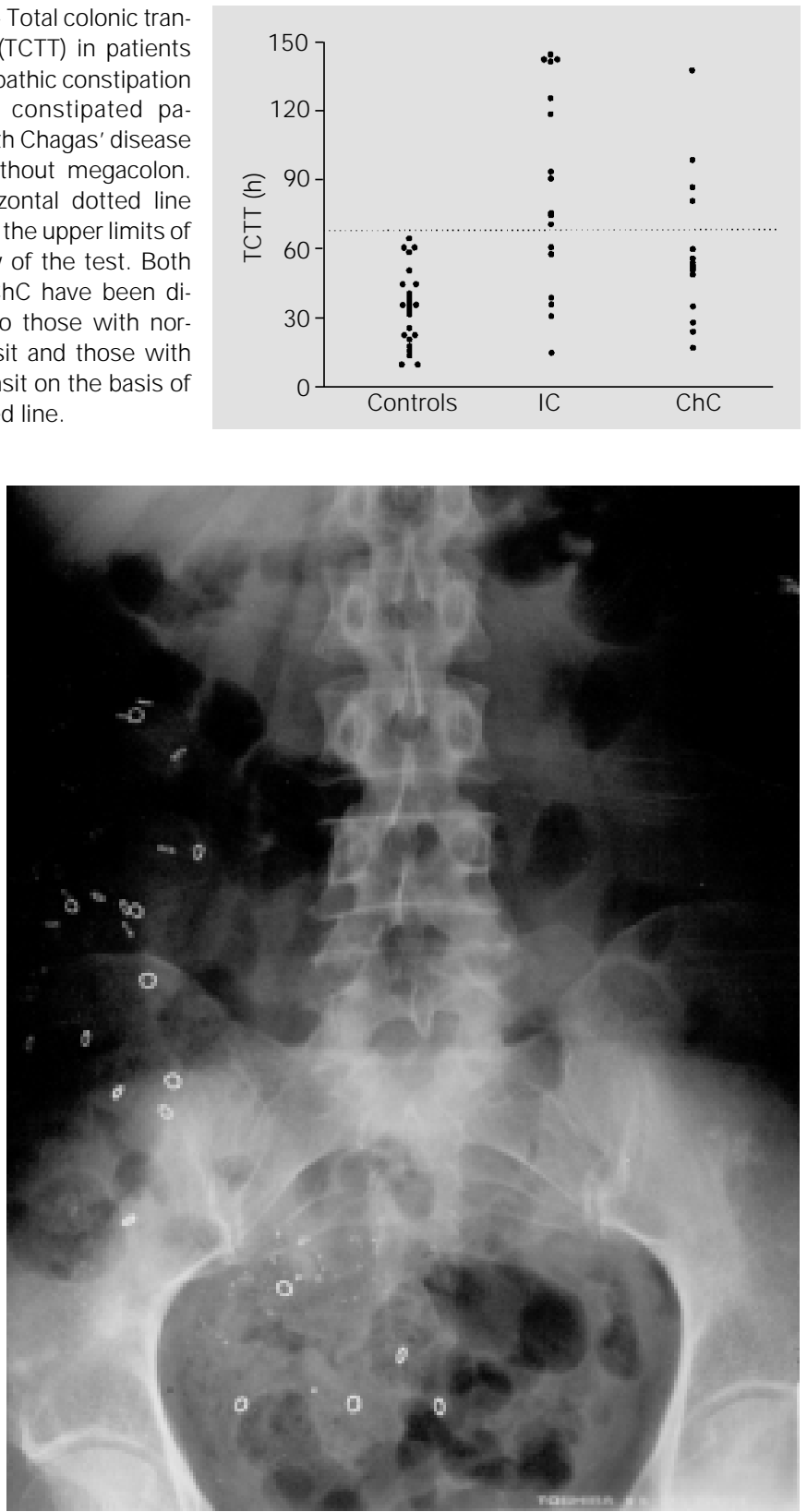

Figure 2 - Colonic inertia in a constipated patient with Chagas' disease (ChC). An X-ray obtained on day 7 shows stasis of the radiopaque markers in the ascending colon. when a decrease of markers was observed on the X-ray. IC and ChC patients were divided according to total CTT into those with "normal transit" and those with "slow transit", the latter when total CTT was longer than 65 $\mathrm{h}$ (Figure 1). Slow colonic transit was shown in $65 \%$ of IC (11 out of 17, 10 females) and $27 \%$ of ChC (4 out of 15, 3 females; $\mathrm{P}=$ 0.03 ). There was no difference between slow transit IC and slow transit ChC patients in total CTT (Table 2). In addition, all patients with prolonged transit reported the chronic use of laxatives.

Segmental CTT. The study of the segmental CTT classified slow colonic transit patients into the subgroups previously defined (Figures 2-4). Among IC patients, $41 \%$ (7 of 17) had a pattern of colonic inertia, $12 \%$ (2) had hindgut dysfunction, $6 \%$ (1) had outlet obstruction, and 6\% (1) showed a prolonged total CTT with normal segmental transit time. Among ChC patients, $13 \%$ (2) showed a pattern of colonic inertia, 7\% (1) had hindgut dysfunction and 7\% (1) had outlet obstruction.

\section{Discussion}

The study of total and segmental colonic transit times with radiopaque markers proved to be a simple, practical and reliable method. The results obtained for our control group are comparable to those described in the literature, including a Brazilian study (11). No significant difference in colonic transit times was found between our male and female controls. Gender effect on colonic transit time has been controversial. Many studies have reported a more prolonged colonic transit in women $(10,11)$. However, these differences have been recently attributed to subject selection $(12,13)$. It has been suggested that many women recruited as healthy controls may suffer from irritable bowel syndrome. It is possible that our routine of asking subjects about changes in bowel habits induced by stress contributed to our findings 
of similar results for men and women. Age also did not influence colonic transit time, confirming previous reports (10).

Colonic transit of radiopaque markers divided both IC and $\mathrm{ChC}$ patients into those with normal CTT and those with prolonged CTT. The complaints of constipation in patients with normal transit time have been associated either with a low fiber diet or with psychological disorders (14). Since the ingestion of fibers varied among our patients, and considering that a fiber supplement may be helpful to exclude a low fiber intake as a cause of constipation (12), the diets of our patients were enriched with $20 \mathrm{~g}$ of fiber. Although it seems reasonable to assume that most of our patients with normal transit were constipated for dietary reasons, it is difficult to determine it from our data, since previous CTT studies without fiber supplement had not been performed on these patients. Likewise, our study was not designed to assess the role of psychological factors in these patients.

Although the symptoms of constipation were similar for all patients of both groups, slow colonic transit was observed only in $27 \%$ of ChC patients and $65 \%$ of IC patients. These findings agree with several studies which have demonstrated the limited usefulness of clinical symptoms and physical examination in distinguishing constipated patients with normal or delayed colonic transit (15). Therefore, measurements of colonic transit time provide an objective assessment for this heterogeneous condition.

The proportion of slow colonic transit observed among our ChC patients was similar to that reported by Pemberton et al. (16) who found a demonstrable abnormality in

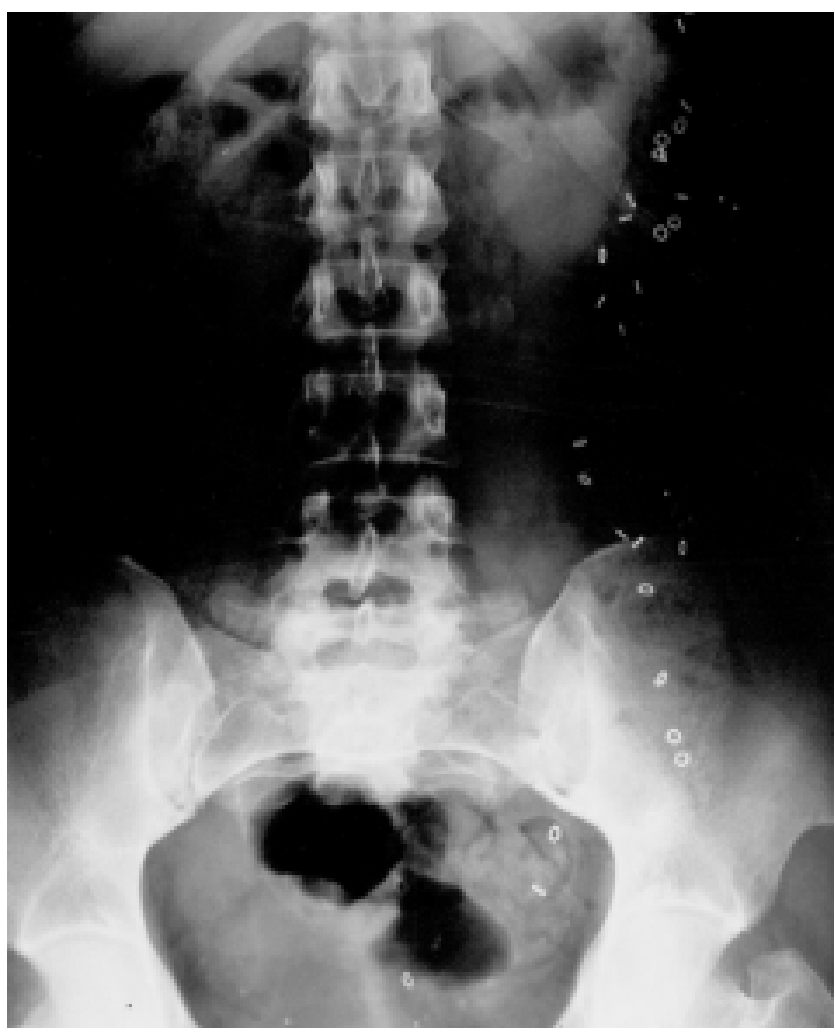

Figure 3 - Hindgut dysfunction in a patient with idiopathic constipation (IC). An abdominal X-ray taken on day 7 shows stasis of radiopaque markers in the left colon.

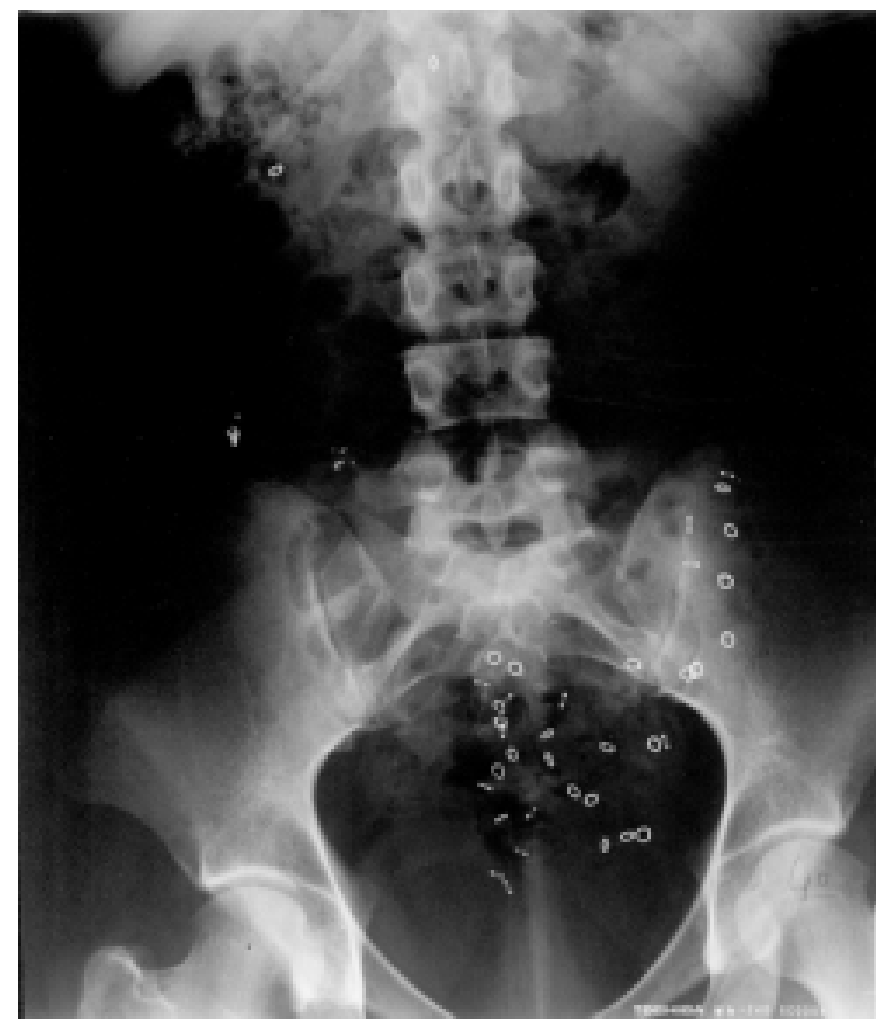

Figure 4 - Outlet obstruction in a patient with idiopathic constipation (IC). An X-ray taken on day 4 shows aggregation of markers in the rectosigmoid. The same pattern was observed on day 7 . 
$29 \%$ of 277 patients with constipation seen at the Mayo Clinic. However, the frequency of colonic transit dysfunction reported in the literature varies widely (30-80\%) (17). It has been suggested that these abnormalities may be more frequent among constipated patients referred to tertiary gastroenterology practices. This might be one explanation for the higher frequency of slow transit found among our IC patients, all of them referred to our clinic for the evaluation of constipation.

One possible pathogenic mechanism for prolonged colonic transit in $\mathrm{ChC}$ patients may be the colonic denervation due to Chagas' disease. Alternatively, slow transit in these patients may be associated with the same pathogenic factors related to idiopathic constipation. Abnormalities of the myenteric and submucosal plexuses have been shown in colonic tissue of patients with idiopathic constipation submitted to colectomy (18). One of the factors implicated in the enteric neuropathy shown by those patients is the long-term use of laxatives (19). It is noteworthy that the chronic use of laxatives was reported by all IC and $\mathrm{ChC}$ patients with slow colonic transit.

Moreover, slow transit patients of both groups also had in common the female preponderance and the low rate of delayed rectosigmoid transit. Our data agree with those of studies of idiopathic constipation which have shown that slow colonic transit is almost exclusively confined to women $(20,21)$. On the other hand, in contrast to the higher proportion of females found in our $\mathrm{ChC}$ group, the proportion of males and females is almost the same among patients with chagasic megacolon (22).

Colonic inertia was the main pattern of colonic dysfunction, observed in $43 \%$ and $13 \%$ of IC and ChC patients, respectively, followed by hindgut dysfunction and outlet obstruction. Based on the knowledge of the colonic involvement in Chagas' disease, which shows a preferential dilation of rectosigmoid (23), a delayed rectosigmoid transit might be expected as the main dysfunction in our ChC patients. However, despite the small number of $\mathrm{ChC}$ patients with slow transit, the abnormalities detected apparently followed the same distribution as seen for IC patients: colonic inertia, hindgut dysfunction and outlet obstruction, the latter present in only one chagasic patient.

It is tempting to assume from the data discussed above that the colonic dysfunction found in this particular group of patients with Chagas' disease may be related to the same underlying factors responsible for idiopathic constipation, such as the denervation induced by laxative abuse. Our selection of chagasic patients excluded those with esophagopathy, a fact that may have accounted for the low rate of rectosigmoid transit abnormalities in this group. It is known from Chagas' disease natural history that megacolon is recognized later than megaesophagus, due to either a slower evolution or to a delay in seeking medical care (22). However, previous pharmacological studies investigating denervation (4) have reported that $20 \%$ of cases of nondilated sigmoid colon in patients with megaesophagus showed hyper-reactivity to metacholine. Therefore, additional studies of colonic transit time in patients with megaesophagus are indicated.

\section{Acknowledgments}

We are grateful to Dr. Eros Antônio de Almeida and Dr. Maria Elena Guariento of the Chagas' disease study group (GEDOCH), UNICAMP, for their assistance. 


\section{References}

1. Drossman DA, Sandler RS, McKee DC \& Lovitz AJ (1982). Bowel patterns among subjects not seeking health care. Use of a questionnaire to identify a population with bowel dysfunction. Gastroenterology, 83: 629-634.

2. Meneghelli UG (1985). Chagas' disease: a model of denervation in the study of digestive tract motility. Brazilian J ournal of Medical and Biological Research, 18: 255264.

3. Macedo J FS, Meneghelli UG, Oliveira RB, Godoy RA, Troncon LEA \& Dantas RO (1986). Effect of CCK-OP and intraduodenal administration of essential amino acids on intraluminal pressures of sigmoid and rectum in patients with chagasic megacolon. Digestive Diseases and Sciences, 31: 145-150.

4. Vieira CB, Godoy RA, Meneghelli UG \& Carril CF (1966). Resposta do cólon sigmóide não ectásico à metacolina na forma crônica da moléstia de Chagas. Arquivos de Gastroenterologia, 3: 21-26.

5. Meneghelli UG, Godoy RA, Oliveira RB, Santos J CM, Dantas RO \& Troncon LEA (1983). Effect of pentagastrin on the motor activity of the dilated and nondilated sigmoid and rectum in Chagas' disease. Digestion, 27: 152-158.

6. Habr-Gama A, Raia A \& Correa Netto A (1970). Motility of sigmoid colon and rectum: Contribution to the pathophysiology of megacolon in Chagas' disease. Diseases of the Colon and Rectum, 14: 291304.

7. Meneghelli UG, Godoy RA, Macedo J FS, Oliveira RB, Troncon LEA \& Dantas RO (1982). Basal motility of dilated and nondilated sigmoid colon and rectum in Chagas' disease. Arquivos de Gastroente- rologia, 19: 127-132.

8. Oliveira RB, Rezende Filho J , Dantas RO \& lazigi N (1995). The spectrum of esophageal motor disorders in Chagas' disease. American J ournal of Gastroenterology, 90: 1119-1124.

9. Arhan P, Devroede $G$, J ehannin B, Lanza M, Faverdin C, Dornic C, Persoz B, Tétreault L, Perey B \& Pellerin D (1981). Segmental colonic transit time. Diseases of the Colon and Rectum, 24: 625-629.

10. Metcalf $A M$, Phillips SF, Zinsmeister AR, MacCarty RL, Beart RW \& Wolff BC (1987). Simplified assessment of segmental colonic transit time. Gastroenterology, 92: 40-47.

11. J orge J MN \& Habr-Gama A (1991). Tempo de trânsito colônico total e segmentar: análise crítica dos métodos e estudo em indivíduos normais com marcadores radiopacos. Revista Brasileira de Coloproctologia, 11: 55-60.

12. Chaussade $\mathrm{S}$, Roche $\mathrm{H}$, Khyara A, Couturier D \& Guerre J (1986). Mesure du temps de transit colique (TTC): description et validation d'une nouvelle technique. Gastroentérologie Clinique et Biologique, 10: 385-389.

13. Bouchoucha $M$, Devroede $G$, Arhan $P$, Strom B, Weber J, Cugnenc PH, Denis P $\&$ Barbier J P (1992). What is the meaning of colorectal transit time measurement? Diseases of the Colon and Rectum, 35: 773-782.

14. Wald A (1986). Colonic transit time and anorectal manometry in chronic idiopathic constipation. Archives of Internal Medicine, 14: 1713-1716.

15. Chaussade S, Khyari A, Roche H, Garret M, Gaudric M, Couturier D \& Guerre J (1989). Determination of total and seg- mental colonic transit time in constipated patients. Results in 91 patients with a new simplified method. Digestive Diseases and Sciences, 34: 1168-1172.

16. Pemberton JH, Rath DM \& Ilstrup DM (1991). Evaluation and surgical treatment of severe chronic constipation. Annals of Surgery, 214: 403-411.

17. Surrenti E, Rath DM, Pemberton JH \& Camilleri M (1995). Audit of constipation in a tertiary referral gastroenterology practice. American J ournal of Gastroenterology, 90: 1471-1475.

18. Kamm MA (1991). Constipation. In: Kamm MA \& Lennard-J ones J E (Editors), Gastrointestinal Transit. Pathophysiology and Pharmacology. Wrightson Biomedical Publishing Ltd., Petersfield, UK, 133-140.

19. Riemann J F \& Schmidt H (1982). Ultrastructural changes in the gut autonomic nervous system following laxative abuse and in other conditions. Scandinavian J ournal of Gastroenterology, 71: 111-124.

20. Preston DM \& Lennard-J ones JE (1986). Severe chronic constipation of young women: idiopathic slow transit constipation. Gut, 27: 41-48.

21. J ohanson J F, Sonnenberg A \& Koch TR (1989). Clinical epidemiology of chronic constipation. J ournal of Clinical Gastroenterology, 11: 525-536.

22. Rezende J M (1993). Manifestações digestivas da doença de Chagas. In: Dani R \& Castro LP (Editors), Gastroenterologia Clínica. Guanabara Koogan, Rio de J aneiro, 1729-1755.

23. Köberle $F$ (1968). Chagas' disease and Chagas' syndromes: the pathology of American trypanosomiasis. Advances in Parasitology, 6: 63-116. 